\title{
THE EFFECT OF LIMBIC DAMAGE ON THE RETENTION AND PERFORMANCE OF A RUNWAY RESPONSE*
}

\author{
Alfred C. RAPHELSON \\ Flint College, University of Michigan \\ ROBERT L. ISAACSON and ROBERT J. DOUgLas $\dagger$ \\ University of Michigan
}

(Received 24 January 1966)

\begin{abstract}
Rats were trained to run a linear runway while hungry for food. Then they were tested for retention, continued performance levels, and extinction after recovery from bilateral damage of the hippocampus, the septal area, or the posterolateral neocortex. Retention losses were observed in animals which had hippocampal or neocortical destruction. Slower running speeds were found in animals with hippocampal destruction, while the running speeds of animals with septal area damage increased. Animals with hippocampal destruction and with septal area damage showed greater resistance to extinction than other groups of animals.
\end{abstract}

\section{INTRODUCTION}

CERTAIN effects of destruction or stimulation of the hippocampus can be interpreted in light of motivational changes. For example, hippocampectomized rats have been reported to acquire a conditioned avoidance response faster and extinguish it more slowly [1], be more resistant to extinction in a runway [2,3], enter more cells of a Hebb-Williams maze [4], and appear to be more readily shaped in an operant box than normal animals or animals with lesions of the posterolateral neocortex $[5,6]$. A higher level of motivation could explain the ineffective performance of hippocampal ablates in passive avoidance situations [2,7], and the reduced disturbances of performancc produced by distracting stimuli [8]. A similar line of reasoning could be used in interpreting behavioral defects of hippocampal destruction if one accepts the view that increased drive or arousal can detrimentally influence behavior in situations involving competing responses [9]. KIMBLE [4] and KAADA et al. [10] have shown behavioral losses in complex tasks compatible with such a view.

The above explanation could be extended to studies using animals with lesions of the septal area. For example, such lesions have been found to produce "emotional reactivity" or "irritability" [11, 12], increased "excitement" over food reward [13], deficiencies in

* The research was carried out while the first author was in a National Science Foundation Research Participation Program for College Teachers of Psychology at the University of Michigan, 1963. Support for certain aspects of the research was from Grant DA-MD-49-193-64-G120 from the Surgeon General, U.S. Army to R.L.I. A brief version of this paper was presented at the 1964 meeting of the Midwestern Psychological Association, St. Louis, Missouri, U.S.A. U.S.A.

$\dagger$ Present address: The Department of Psychiatry, Stanford Medical Center, Stanford, California, 
passive avoidance behavior [14, 15], increases in bar presses during nonreinforced conditions and slower extinction of a bar-pressing response [16].

This type of explanation of limbic area destruction is the more appropriate since the demonstration of increased water intake by animals with septal area destruction [17] and the likely significance of such increased thirst for the interpretation of "fear-motivated" problems [18]. Furthermore, there have been reports of increased food consumption on the part of animals with lesions in the septal area [19].

The purpose of this study was to determine whether the hypothesis that animals with hippocampal destruction have increased motivation for food or water is sufficient to explain the behavioral effects observed following such lesions. One of the principle requirements in determining motivational effects is the need for preoperative observations. Without these it is difficult to evaluate the experimental animals' performance against a "normal base line." An adequate test of the drive facilitation hypothesis would involve preoperative training to asymptotic performance on a task sensitive to changes in motivation. After sufficient recovery from surgery, further performance trials could be administered under the same drive conditions. The effects of the limbic damage on retention and subsequent performance could then be evaluated.

CotTon [20] has shown that a simple runway is such a situation. He ran animals under varying drive levels and demonstrated that the effect of increased drive on runway behavior was an increase in running speed. King replicated this result and supplied evidence that the primary effect of drive variation appeared to be upon the running response itself rather than the number of competing responses that appeared in the situation [21].

In the present study all animals were given fifty rewarded trials in an 8-ft runway, then divided into six groups closely matched on asymptotic running speeds. Surgery was performed on three experimental groups (Radical Bilateral Hippocampal lesions, Partial Hippocampal lesions, Septal lesions) and three control groups (Cortical Control lesions, Ablation Sham Operates, Electrolytic Sham Operates). Thirty postoperative rewarded trials were administered and then all Ss were given twenty massed extinction trials.

\subsection{General procedures}

\section{METHOD}

Data were obtained from 30 naive male hooded rats from the Windsor Biological Gardens. The Ss were approximately 90-days old and weighed between $270-340 \mathrm{~g}$. when the experiment began. They were maintained throughout the experiment at this approximate weight by daily, 1-hr feedings of ground Purina Lab Chow fortified with dry milk and corn oil in quantities adjusted for each animal. Throughout the experiment, Ss were trained under $21 \mathrm{hr}$ food deprivation. Water was available ad lib in their living cages.

\subsection{Apparatus}

The apparatus was a straight alley runway painted fiat black with inside dimensions of $96 \times 5 \times 5$ in. A clear plastic top covered the runway. One guillotine door located $12 \mathrm{in.} \mathrm{down} \mathrm{the} \mathrm{runway} \mathrm{incorporated}$ a zone serving as a "start box" and a second guillotine door located 66 in. farther down the runway marked the beginning of the 18-in. "goal box." Response latency was the time required for the animal to break a photo-cell beam 6 in. past the starting box door following the raising of this door. Running speed was measured between this photocell and another one located 6 in. inside the goal box door. Both photocell beams were passed through i.r. filters.

A $2 \times 5 \times \frac{1}{4}$ in. partition was set $2 \frac{1}{2}$ in. in front of the back wall of the goal box. This shielded from view a glass dish which served as a food receptable. One $97 \mathrm{mg}$ Noyes food pellet was used as a reward.

The experiment was conducted in the dark with the only light present being a dim, shaded bulb located $3 \mathrm{ft}$ from the runway to allow $E$ to record data from the timers.

\subsection{Handling}

Previous to the start of the experiment all Ss received 10 days of handling and gentling. Subjects were placed six at a time on a $4 \times 3 \mathrm{ft}$ sawdust-filled table and constantly handled for $30 \mathrm{~min}$. Slats of wood 
were placed between the sides of the table and Ss were encouraged to walk across them. Pellets of food identical to those used as rewards were fed to them at the end of runs on the slats. By the end of the handling period all Ss were running easily along the slats.

After surgery, all Ss were placed for 3 days on an ad lib diet with Tetracyn added to their water. Then, Ss were returned to their previous maintenance schedule. Their weights were returned to their preoperative levels, and daily handling was begun. The recovery period continued for 2 weeks.

\subsection{Preoperative training}

All Ss were given fifty rewarded trials in the runway in blocks of five trials a day, during the hours of $10.00 \mathrm{a} . \mathrm{m}$. and $2.00 \mathrm{p} . \mathrm{m}$. Ss were run with a minimal intertrial interval of $5 \mathrm{~min}$ throughout the preoperative, postoperative, and extinction trials.

\subsection{Behavioral measures}

Response latency (the time for getting out of the start box) and running speed measures (elapsed time between start box and goal box) were obtained on all trials as well as a count of the number of pauses and retracings. A maximum of $180 \mathrm{sec}$ was allowed each $S$ to traverse the runway. If the goal area was not reached within this time limit, $\mathbf{S}$ was removed from the runway and placed in the goal box. All Ss were removed from the goal box $10 \mathrm{sec}$ after they had eaten the reward pellet or after $2 \mathrm{~min}$ if they failed to eat.

Latency and running speed measures were converted to feet per second (ft/sec) and an average computed for each day's performance for each S. At the end of 10 days of preoperative training, Ss were divided into groups of five animals in such a manner that the best match possible was made between groups on average running speed on Day 10 (Trials 46-50). Alternate Ss were also assigned in rank order to each group.

Surgical procedures were accomplished between 3 and 5 days after the end of preoperative training.

\subsection{Surgery}

2.6.1. Radical Bilateral Hippocampal lesions. Surgery was performed after administration of Nembutal $(40 \mathrm{mg} / \mathrm{kg}), 0.04 \mathrm{mg}$ of atropine sulfate, and 100,000 units of penicillin. A midline incision was made in the scalp and the temporal muscles were freed from their dorsal and lateral insertions. Suitable holes were drilled in the skull and enlarged dorsally and laterally by rongeurs. The dura was then cut and using a blunted 21-gauge hypodermic needle connected to an aspirator, the cortical tissue overlying the hippocampus was removed. The exposed hippocampus was then removed medially and ventrally. After bleeding had been arrested, Gelfoam was inserted in the wound, the temporal muscles replaced, and the scalp closed with silk suture thread.

2.6.2. Partial Bilateral Hippocampal lesions. This procedure was the same as described above except that only the more dorsal aspects of the hippocampus were removed.

2.6.3. Bilateral Cortical Control lesions. This procedure was the same as described in $\$ 2.6 .1$ above except that a greater amount of cortical tissue was removed and the hippocampus was left intact after neocortical aspiration. This control group was to study any effects of cortical damage since the hippocampectomized Ss also had such damage. The greater amount of cortical damage was designed to control for diaschsis.

2.6.4. Bilateral Septal lesions. These lesions were produced by d.c. fulguration using a Kreig-Johnson Sterotaxic instrument and appropriate Coordinates. The Ss were prepared for surgery as described above with the following changes: the temporal muscles were not freed from their insertions. The Ss were placed in the sterotaxic instrument and small holes drilled through the skull above the intended electrode locations. The positive electrode was inserted through the hole according to the following coordinates (22): $1.8 \mathrm{~mm}$ anterior to bregma; $3.0 \mathrm{~mm}$ lateral to the midline; and $4.5 \mathrm{~mm}$ below. The surface of the brain at an angle of $25^{\circ}$ toward the midline. The negative electrode was placed in the anus. The lesions were made bilaterally with minimal delay between the times of destruction.

2.6.5. Ablation Sham Control. The Ss in this group were prepared surgically as were the first two groups, but no holes were drilled through the skull nor was any bone removed.

2.6.6. Electrolytic Sham Control. A sixth group was prepared as controls for the septal lesion group. However, at the end of its preoperative trials, the running speeds of the Ss averaged significantly less than the average of $\mathrm{Ss}$ in the other five groups. Hence, it could not qualify for comparison with the other matched groups. Nevertheless, it was prepared for surgery as a control for the Septal Group although interpretation of its performance must be limited.

After administration of Nembutal, Ss were placed in the stereotaxic instrument, midline incision made, and holes made through the skull. Then, they were removed from the instrument and sutured. The group was put through all the postoperative conditions and at the time of the beginning of extinction training was performing at a level comparable to the other five groups. Hence, its data was included in the analysis of that phase of the experiment. 
During the recovery period, the extreme emotionality often described by others (e.g. [23]) was observed in the Septal Group. This behavior lasted for $\mathbf{1 0}$ days during which time the daily handling was continued. The Ss receiving the radical hippocampectomies evidenced some emotionality during the first 3 days of handling, particularly when being removed from their cages, but this dissipated rapidly and was unobservable after the 4th postoperative day.

\subsection{Postoperative training}

At the end of the recovery period, daily training was begun under the same conditions as preoperatively. Blocks of five trials a day were given for 6 days. Response latencies and running speeds were obtained.

All Ss were then given twenty massed extinction trials. The first trial was rewarded, and then nineteen unrewarded trials were given.

All time scores were converted to the feet per second $(\mathrm{ft} / \mathrm{sec})$ measure. The pre- and postoperative trials were analyzed as follows: an average was computed for each $\mathbf{S}$ for each day's performance (block of five trials). For each group an average was computed of the average scores made by Ss in the block of five trials. The last block of preoperative trials (Trials 46-50) and the six postoperative blocks were evaluated by analysis of variance for a two factor experiment with repeated measurements. Tests of simple main effects were carried out when appropriate, as were individual mean comparisons, by the Tukey method [24]. The extinction data were analyzed in a similar manner except that two-trial blocks were used. Since the response latency and running speed measures showed the same trends, only the more reliable running speed data will be presented.

\subsection{Histology}

After the experiment the brain-damaged Ss were sacrificed and perfused intracardially with 10 per cent formalin. The brains were dehydrated, then infiltrated with, and embedded in, paraffin. Sections were made at $15 \mu$ and every twentieth section through the lesion retained and stained with thionin or the luxol blue-cresyl echt violet counterstain [25]. Reconstructions of the hippocampally lesioned Ss are presented in Fig. 1 and those of the cortical controls and septal damaged Ss in Fig. 2.

2.8.1. Radical Hippocampal Group. All Ss in the Radical Hippocampal Group had extensive damage to this structure. In all cases the entire dorsal region was destroyed and in most cases the ventral portion was destroyed below the level of the rhinal fissure. One $S(10 \mathrm{LH})$ suffered slight unilateral, surgicallyinduced, damage to the lateral nucleus of the thalamus, and in another S (33LH) there was unilateral thalamic gliosis in the same region. However, neither animal showed behavioral characteristics that varied from others of their group.

2.8.2. Partial Hippocampal Group. All Ss in the Partial Hippocampal Group received damage restricted to the dorsal portions of the structure. In two Ss there was slight bilateral thalamic damage in the area of the lateral nucleus but their behavior was not different from the other animals in this group.

2.8.3. Cortical lesions. Two Ss in the Cortical Group had slight damage of the dorsal hippocampus, unilaterally in one case (17C) and bilaterally in the other (36C). Both Ss showed behavior that was different from the other members of their group on both the postoperative and extinction trials. In both situations they performed like animals suffering intentional damage to the hippocampus.

2.8.4. Septal Group. In the Ss of the Septal Group, damage to this area was extensive. In all five Ss the lateral and medial septal nuclei were almost completely destroyed. One $S(5 S)$ was found to have damage in the area of the diagonal band and anterior commissure. In S $11 \mathrm{~S}$ there was damage to the primordial hippocampus, anterior commisure, and nucleus accumbens. In S $10 \mathrm{~S}$ there was damage to the anterior hypothalamus (periventricular nucleus) as well as the paraventricular and parataenialis nuclei of the thalamus. Subject $8 \mathrm{~S}$ evidenced similar hypothalamic damage but no thalamic involvement. Subject $24 \mathrm{~S}$ had minor thalamic but little hypothalamic damage. Despite this variety of extraneous damage in the septal group, the animals of this group performed with amazing homogeneity on the postoperative training and extinction trials.

\section{RESULTS}

\subsection{Pre- and postoperative performance}

Figure 3 summarizes pre- and postoperative performance in terms of mean running speed. The only significant between-group differences were on Postoperative Blocks 2 (Trials 56-60), 3 (Trials 61-65), and 6 (Trials 76-80) $(F=3.73,3.58$, and 3.27 respectively, $\mathrm{df}=4 / 20, P<0.05)$. On all of these blocks of trials the Septal Group ran significantly faster than the Radical Hippocampal Group and on Block 3 (Trials 61-65) they also ran faster than the Partial Hippocampal Group. 

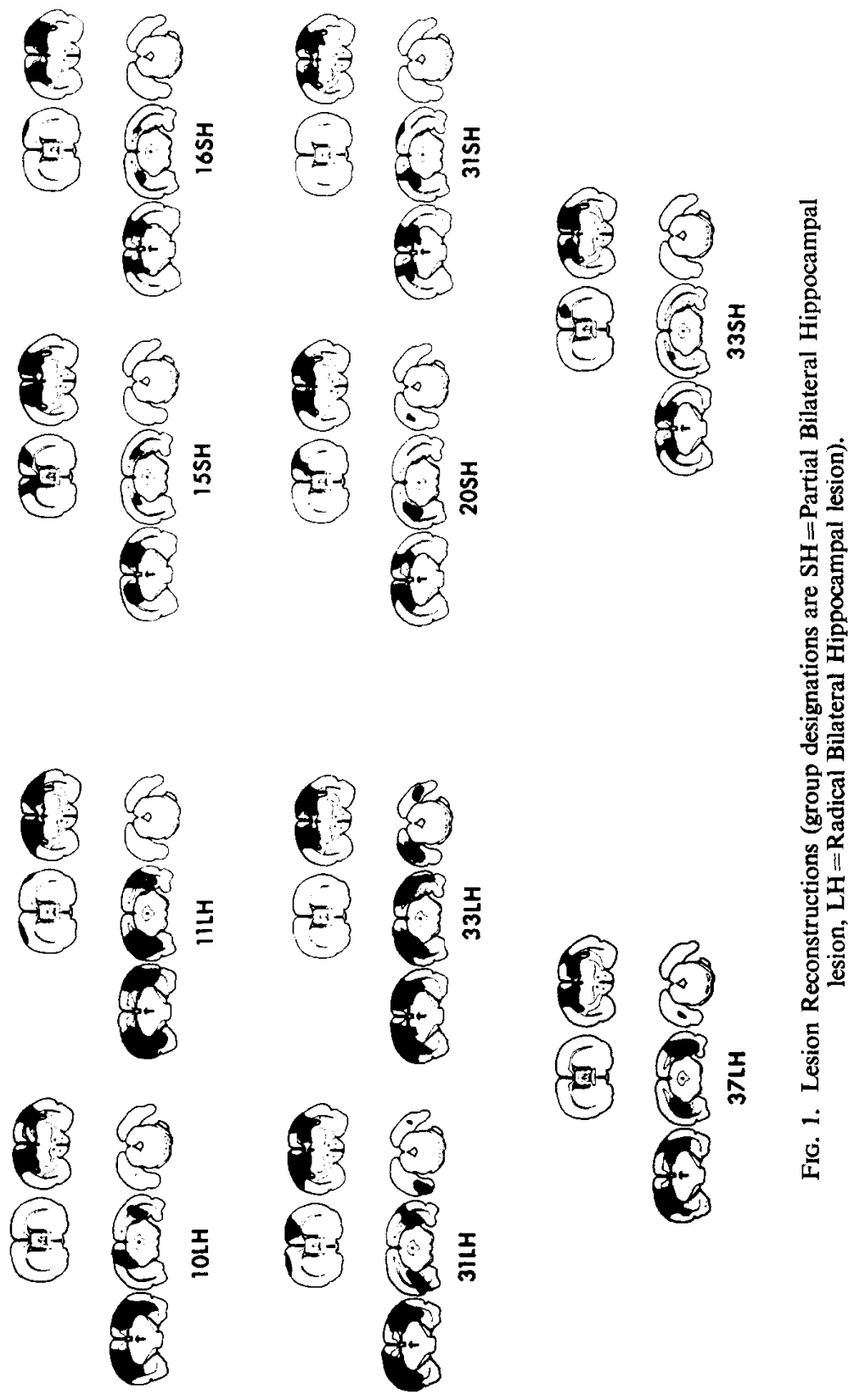

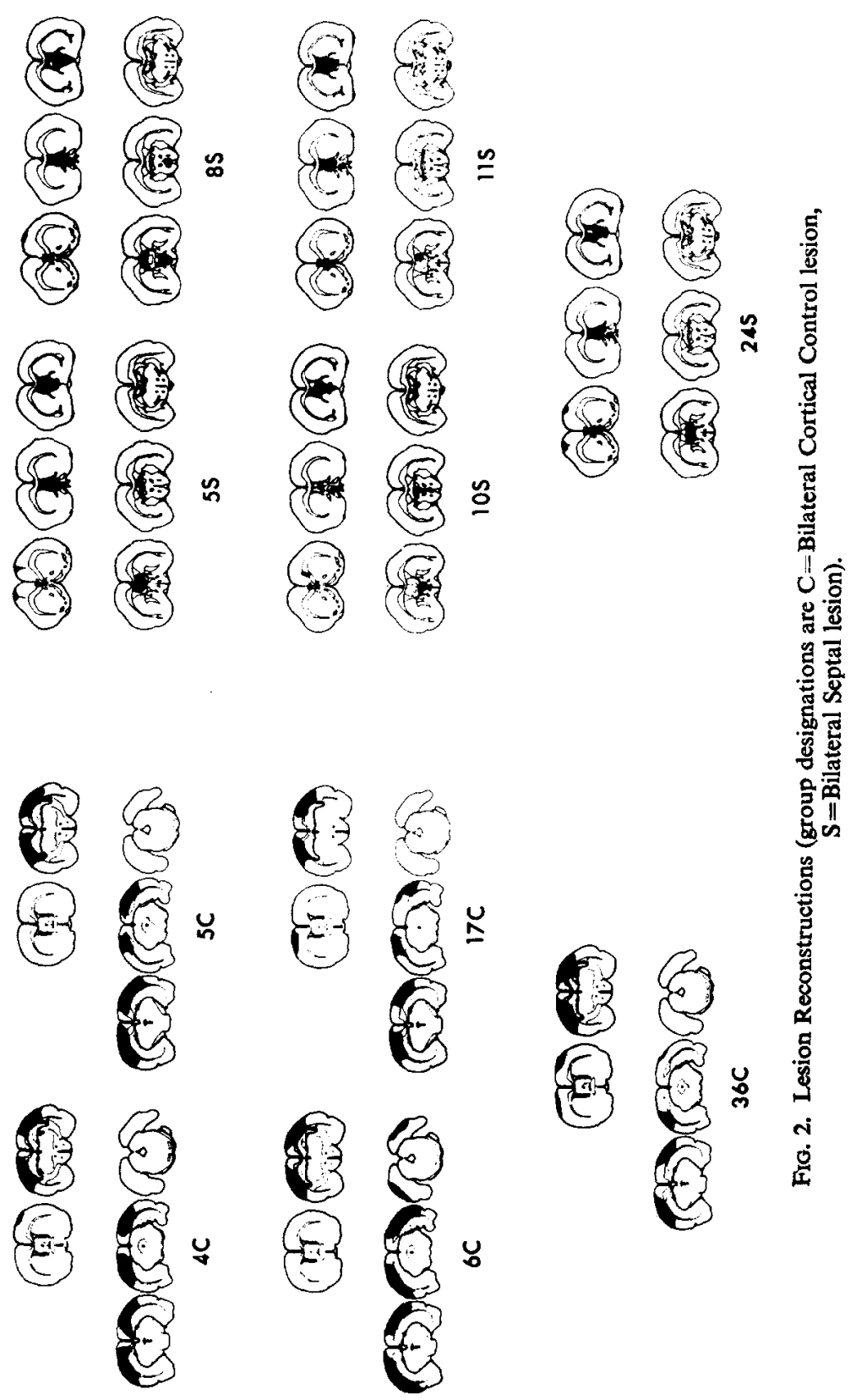


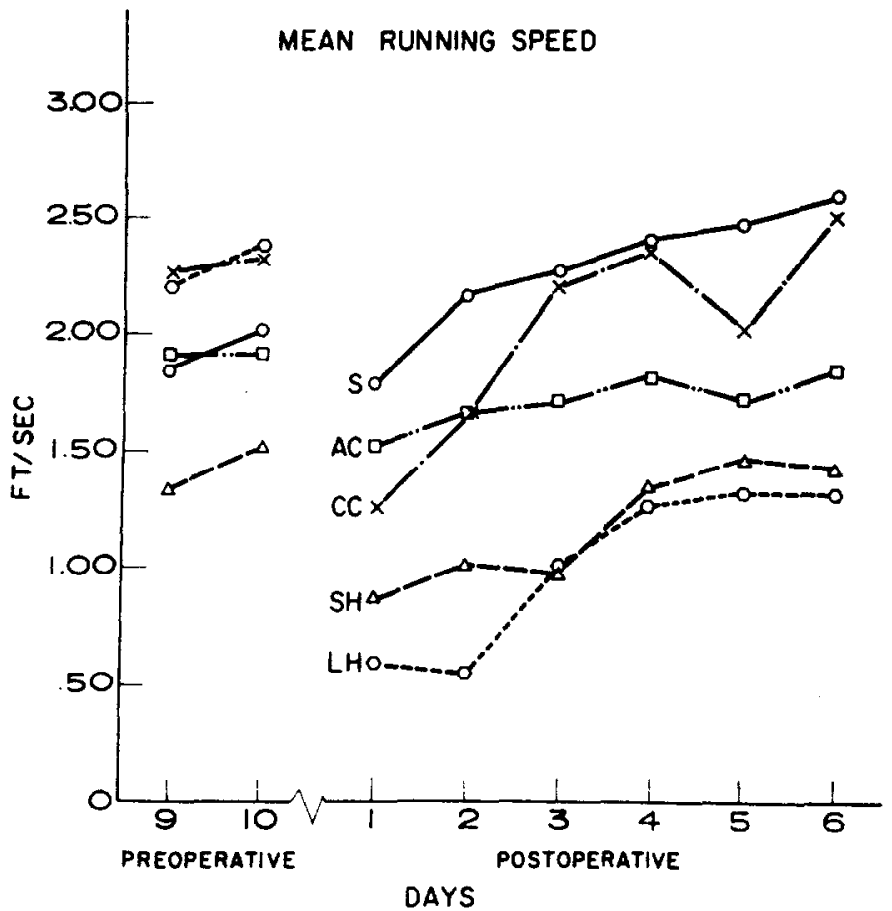

Fig. 3. Mean running speed in feet per second for groups on pre- and postoperative trials (group designations are $\mathbf{S}=$ Bilateral Septal lesion, $\mathbf{S H}=$ Partial Bilateral Hippocampal lesion, LH $=$ Radical Bilateral Hippocampal lesion, $\mathrm{CC}=$ Bilateral Cortical Control lesion, $\mathrm{AC}=$ Ablation Sham Control).

The tests of the within-group differences revealed that only the Ablation Sham Group failed to show any significant change between the pre- and postoperative trials. The Radical Hippocampal Group showed the most dramatic change. Performance in every one of the postoperative blocks was significantly slower than on the last preoperative block $(F=11.12$, df $=6 / 120, P<0.01)$. The Partial Hippocampal Group showed a less dramatic change revealing only a significant drop from the last preoperative to the first postoperative block $(F=2.17, \mathrm{df}=6 / 120, P<0.05)$. This group's performance, however, showed the same trend as the Radical Hippocampal Group, in that running speeds in every postoperative block of trials was less than in the last preoperative block.

The Septal Group showed an entirely different pattern with running speeds increasing throughout the postoperative trials $(F=2.26, \mathrm{df}=6 / 120, P<0.05)$. Its lowest level of performance was in the first postoperative block which was not significantly different from its preoperative level. The running speeds in the last block (Trials 76-80) were significantly faster than the running speeds in the first postoperative block.

The Cortical Group showed a significant drop in performance on the first postoperative block but quickly returned to its preoperative level of performance $(F=5.88$, $\mathrm{df}=6 / 120, P<0.01$ ). No other block differed significantly from this preoperative level.

In summary, only the two hippocampal groups and the cortical group showed a significant decrease in performance between the last preoperative and the first postoperative trials. Only the Radical Hippocampal Group continued to perform at significantly lower 
running rates throughout the postoperative training. The Septal Group did not show a significant postoperative decrease and, in fact, increased significantly throughout the postoperative trials. Their fastest running times were in the last postoperative block of trials.

\subsection{Extinction measures}

The results of the extinction trials are presented in Fig. 4.

MEAN RUNNING SPEED DURING EXTINCTION

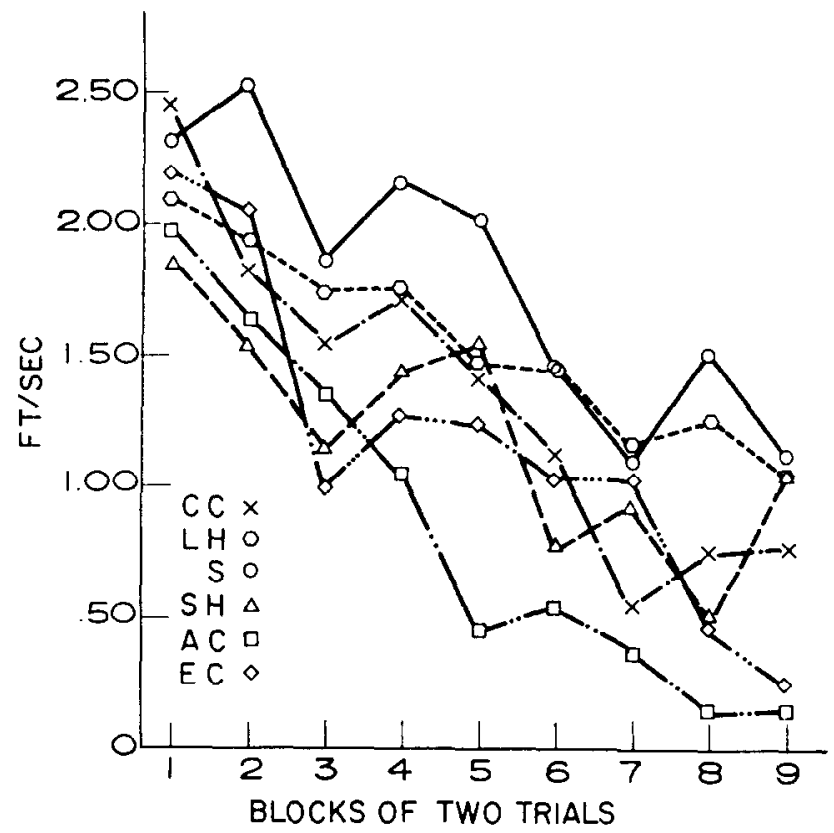

FIG. 4. Mean running speed in feet per second for groups during the extinction trials on Day 1 (group designations are $\mathrm{S}=$ Bilateral Septal lesion, $\mathrm{SH}=$ Partial Bilateral Hippocampal lesion, $\mathbf{L H}=$ Radical Bilateral Hippocampal lesion, $\mathbf{C C}=$ Bilateral Cortical Control lesion, $\mathrm{AC}=$ Ablation Sham Control, EC=Electrolytic Sham Control).

An inspection of the graph reveals that although all six groups show a significant decrease throughout the trials, there is a general trend for the three control groups (Cortical, Ablation Sham, Electrolytic Sham) to decrease at a faster rate than three groups with limbic damage (Radical Hippocampal, Partial Hippocampal, and Septal). Figure 5 shows the results when the three limbic groups are combined and compared with the combined groups. Tests of the simple main effects showed that significant differences between the two groups occurred on Blocks $5(P<0.05), 8(P<0.05)$, and $9(P<0.05)$.

\section{DISCUSSION}

Our results fail to support the view that the behavioral results observed following hippocampal destruction can be explained on the basis of increased motivational levels. In fact animals with such lesions exhibit a decrement in performance postoperatively and over continued training fail to regain their preoperative running rates. 
MEAN RUNNING SPEED DURING EXTINCTION DAY I

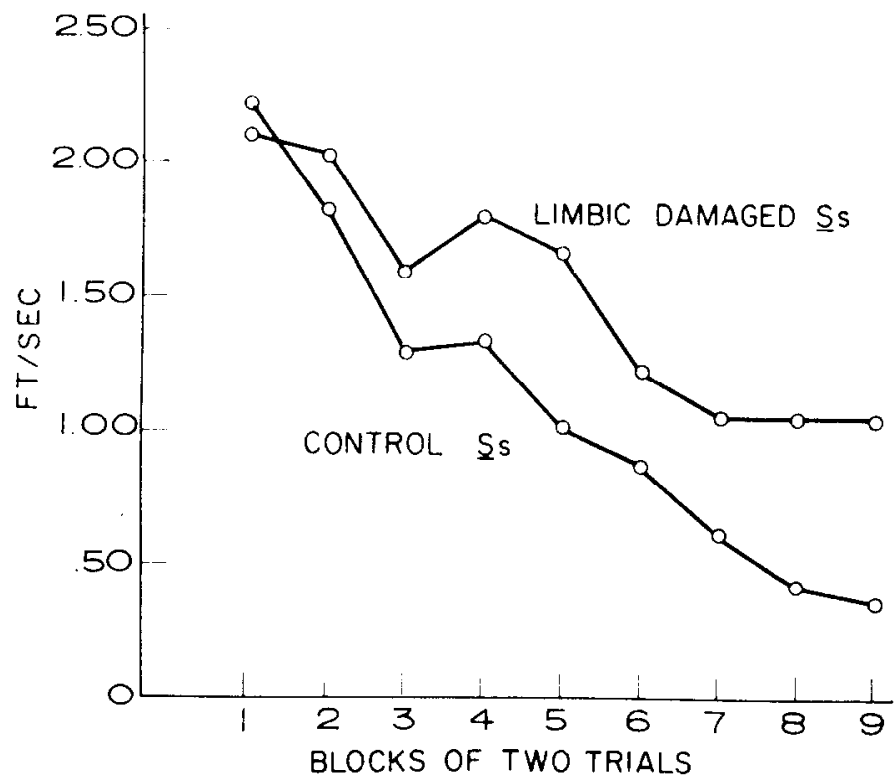

FIG. 5. Mean running speed in feet per second for combined limbic-damaged groups and combined control groups during the extinction trials on Day 1.

On the other hand, rats with septal damage do not show any initial postoperative decline in performance and their running speeds increase over the six postoperative training days. Since the initial period of septal hyperirritability had dissipated before postoperative training began, and presumably would decline further with time, it appears that the increasing running speeds of the animals with septal damage could reflect heightened motivational levels. This observation is compatible with the results of others indicating increased motivational levels following such lesions. The differences in performance of the hippocampal and septal groups suggest that the behavioral similarities often found in other experiments between animals with hippocampal and septal damage can not be founded on similar underlying motivational changes.

Our results indicating a decreased performance level following hippocampal destruction are consistant with observations by CLARK and ISAACSON [5] in which hippocampectomized animals bar-pressed less for water, while thirsty, than normal animals under continuous reinforcement conditions. However, it should be noted that experimental results are not entirely consistant. For example, EHRLICH [26] reported an increase in food-oriented behavior and food consumption in rats with destruction of the fornix. Yet, destruction included the septal area and other adjacent structures in her experiment.

Using a different procedure, Grossman and MOUNTFOrd [27] found an apparent decrease in the motivational level during training in a discrimination task following injection of $\mathrm{KCl}$ into the dorsal hippocampus.

Animals may differ in their reactions to changes in reinforcement conditions or other experimental factors, e.g. punishment, frustration, etc. The increase in resistance to extinction on the part of the animals suffering limbic system lesions in the present study, 
and in previous ones, could reflect altered emotional reactivity to nonreinforcement. Since the change from continuous reinforcement to partial reinforcement undoubtedly is frustrative, increased resistance to extinction could represent an overaction to frustrative nonreward. When hippocampectomized rats are shifted to a partial reinforcement schedule, their response rates greatly exceed those of the normal or control animals [28].

A similar type of explanation could be used to explain the persistance of hippocampally lesioned animals in passive avoidance situations, if one assumes the shock received at the goal box to represent a frustrative event. Thus, the possibility must be entertained that one effect produced by destruction of the hippocampus is a greater responsiveness to frustrating circumstances, despite the fact that overall motivation under conditions of deprivation is not increased.

The relationship among brain lesions, performance, and motivation has been recognized since Pribram [29] reported that changes in deprivation conditions can favorably affect the delayed-response performance of animals following prefrontal destruction. Analyses of the changes in behavior of animals suffering prefrontal damage following experimental manipulations which appeared to be motivational in character were thought to produce their effects by changing the distinctiveness of situational cues. However, the deficits produced by such lesions can not be attributed to alterations in motivational changes, as traditionally defined. Pribram has shown that the changes in performance found in the monkey with prefrontal lesions on a fixed interval operant schedule can not be duplicated by strenuous manipulation of deprivation conditions in the normal monkey [30]. Moreover, the changes produced by prefrontal lesions appear to be best described in terms of certain organizational processes essential to efficient performance in situations in which stimuli are unreliable guides for behavior.

Fortunately, there seems to be a convergence of results found among animals of different species following hippocampal destruction. For example, greater resistance to extinction following hippocampal destruction has been found in the cat $[31,32]$, results which are similar to those found in the rat $[3,33,34]$. Other results, comparable to those found in the rat, have been reported in the monkey, as well (e.g. [35]).

The observations of KIMBLE and PRIBRAM [36] that hippocampectomized monkeys were inferior to control subjects in maintaining either self-ordered or externally ordered sequential problems suggest a failure of hippocampectomized animals to exhibit normal amounts of plasticity in behavior, although the mechanisms of such plasticity are not as yet well known. NIKI has reported the impairment of rats with hippocampal destruction on tasks in which an ordered behavioral sequence must be maintained [37].

WEISKRANTZ et al. on the basis of work involving stimulation of the monkey hippocampus, have suggested that the memory deficit following hippocampal destruction in the human may more properly be ascribed to ventral neocortical tissue adjacent to the hippocampus [38]. In the present experiment the decrease of running speeds of the animals suffering neocortical destruction and their subsequent regaining of preoperative speeds could be interpreted as an impairment of memory for this simple behavioral task. Of course, it is problematical whether the neocortex destroyed in our cortical control animals is homologous to the ventral cortex of the temporal lobe in the monkey.

It must be emphasized that the hippocampal lesions made in the rat by aspiration techniques always involve destruction of overlying neocortex. In certain behavioral problems this necessary destruction of cortical tissue does not produce measurable alterations in behavior. However, the destruction of such tissue did produce 
an observable behavioral effect in the present study. In all studies destruction of this tissue may interact with hippocampal destruction, even those in which no direct effect of neocortical destruction is found.

When aspirative lesions of the hippocampus are made in the cat, relatively less neocortical tissue is destroyed than in the rat. Even less is destroyed in the monkey, especially when a ventral approach is used. Therefore, any interactive effects of neocortical destruction and hippocampal destruction likely will be greatest in the rat. As mentioned above, the transient deficit in running speeds in the present experiment following neocortical destruction indicates that the cortical insult, by itself, was not without effect. The failure of the hippocampal animals to regain their former running speeds may reflect a failure of an ability to readjust to the situation. Thus, the hippocampal deficit may represent an impairment of mechanisms which enable the animal with neocortical destruction to use subsequent experiences in regaining efficient performance levels.

The resolution of differences in behavior following hippocampal destruction must depend upon finer evaluation of both the behavioral tasks given the animals and upon consideration of the extent to which other structures or areas are involved with the lesion. Recent investigations of the motivational effects of destruction of the septal areas suggest that it plays an important role in motivational mechanisms. However, the import of the present study is its negative evaluation of motivational increments following destruction of the hippocampus. On the other hand, our evaluations were based upon "traditional views" of motivational variables in animal learning and cannot be considered as indicating that behavioral changes which may be called "motivational" in other, and perhaps more useful, theoretical frameworks (e.g. [39]) do not result from the lesions made in this experiment.

\section{REFERENCES}

1. Isaacson, R. L., Douglas, R. J. and Moore, R. Y. J. comp. physiol. Psychol. 54, 625-628, 1961.

2. IsAacson, R. L. and WiCkelgren, W. O. Science, N. Y. 138, 1104-1106, 1962.

3. Jarrard, L. E., IsaAcson, R. L. and WiCkelgren, W. O. J. comp. physiol. Psychol. 57, 442-444, 1964.

4. Kimble, D. P. J. comp. physiol. Psychol. 56, 273-283, 1963.

5. Clark, C. V. and Isaacson, R. L. J. comp. physiol. Psychol. 59, 137-140, 1965.

6. Schmaltz, L. and Isaacson, R. L. Physiol. Behav. 2, 175-182, 1966.

7. Kimura, D. Can. J. Psychol. 12, 213-218, 1958.

8. WiCkeloren, W. O. and IsAacson, R. L. Nature, Lond. 200, 48-50, 1963.

9. Malmo, B. Psychol. Rev. 64, 276-287, 1959.

10. KaAda, B. R., Rasmussen, E. W. and Kviem, O. Expl. Neurol. 3, 333-355, 1961

11. BRADY, J. V. and NAUTA, W. J. H. J. comp. physiol. Psychol. 46, 339-346, 1953.

12. KING, F. A. J. nerv. ment. Dis. 126, 57-63, 1958.

13. Ellen, P. and Powell, E. W. Expl Neurol. 6, 1-11, 1962.

14. McCleary, R. A. J. comp. physiol. Psychol. 54, 605-613, 1961.

15. KaAda, B. R. J. comp. physiol. Psychol. 55, 661-670, 1962.

16. Schwartzbaum, J. S. J. comp. physiol. Psychol. 58, 217-224, 1964.

17. Harvey, J. A. and Hunt, H. F. J. comp. physiol. Psychol. 59, 49-56, 1965.

18. Harvey, J. A., Kints, C. E., Jacobson, L. E. and Hunt, H. F. J. comp. physiol. Psychol. 59, 37-48, 1965.

19. Simmons, H. J. and Thomas, G. J. Paper read at the 33rd Annual Meeting of the Midwestern Psychological Association, Chicago, May, 1961.

20. Cotron, J. W. J. exp. Psychol. 46, 188-198, 1953.

21. Kimble, G. A. Hilgard and Marquis' Conditioning and Learning. Appleton-Century-Crofts, New York, 1961.

22. DeGroot, J. Verh. K. ned. Akad. Wet. 52, 1-40, 1959

23. Brady, J. V. and Nauta, W. J. H. J. comp. physiol. Psychol. 48, 412-420, 1955. 
24. Winer, B. J. Statistical Principles in Experimental Design. McGraw-Hill, New York, 1962.

25. Kluver, H. and Barrera, E. A. J. Neuropathol. exp. Neurol. 12, 400-403, 1953.

26. Ehrlich, A. J. comp. physiol. Psychol. 56, 390-396, 1963.

27. Grossman, S. P. and Mountford, H. Am. J. Physiol. 207, 1387-1393, 1964.

28. JARRARD, L. E. Psychonom. Sci. 2, 115-116, 1965.

29. Pribram, K. H. J. Neurophysiol. 13, 373-382, 1950.

30. Pribram, K. H. Expl Neurol. 3, 432-466, 1961.

31. Peretz, E. J. comp. physiol. Psychol. 60, 182-185, 1965.

32. Webster, D. B. and VoneIDA, T. J. Expl Neurol. 10, 170-182, 1964.

33. NiKI, H. Jap. psychol. Res. 4, 139-153, 1962.

34. JARrard, L. E. and IsAaCson, R. L. Nature, Lond. 207, 109-110, 1965.

35. Stepien, L. S., Cordeau, J. P. and Rasmussen, T. Brain 83, 470-489, 1960.

36. Kimble, D. P. and Pribram, K. H. Science, N. Y. 139, 824-825, 1963.

37. NiKI, H. Paper read at XXIII International Congress of Physiological Sciences, Sept. 10-12, 1965, Hakone, Japan; and personal communication, 1965.

38. Weiskrantz, L., Mihailovic, Lj. and Gross, C. G. Brain 85, 487-504, 1962.

39. Pribram, K. H. In Nebraska Symposium on Motivation (Edited by Jones, M. R.). Univ. Nebraska Press, Lincoln, 1963.

Résumé-Des rats affamés étaient entrainés à parcourir un chemin linéaire. Ils étaient ensuite testés pour la rétention, la persistance des niveaux de performance et l'extinction après récupération d'atteinte bilatérale de l'hippocampe, de l'aire septale ou du néocortex postérolatéral.

Des déficits de la rétention étaient observés chez les animaux ayant subis des destructions hippocampiques et néocorticale, des ralentissements dans la vitesse du parcours étaient constatés lors des destructions hippocampiques tandis que l'on notait des accélérations en cas d'atteinte de l'aire septale. Les animaux avec destructions hippocampiques et atteintes de l'aire septale montraient une plus grande résistance à l'extinction que les autres groupes d'animaux.

Zusammenfassung - Ratten wurden trainiert, im Zustande Hunger die lineare Strecke einer Rennbahn zu laufen. Danach wurden sie untersucht-nach vorheriger Erholung von beiderseitiger Schädigung des Hippocampus, der Septum-Gegend oder der postero-lateralen Hirnrinde (Neo-cortex) - auf Folgendes: Retention, fortdauernde Leistungsfähigkeit und auf Widerstand gegen Vernichtung. Retentions-Verluste wurden beobachtet in Tieren, welche Hippocampus- oder Rinden-Zerstörung hatten. Verringerte Laufgeschwindigkeiten wurden in Tieren mit Hippocampus-Zerstörung gefunden, während die Laufgeschwindigkeiten von Tieren mit Schädigung der Septum-Gegend zunahmen.

Tiere mit Zerstörung des Hippocampus und mit Schädigung der Septum-Gegend zeigten größeren Widerstand gegen Vernichtung als andere Tiergruppen. 